\title{
Does VC Spur Regional Innovation?
}

\author{
Shun Zhang ${ }^{*}$, Lining Dong ${ }^{2}$ \\ ${ }^{1}$ College of Economics, Jinan University, Guangzhou, China \\ ${ }^{2}$ School of Accountancy, Central University of Finance and Economics, Beijing, China \\ Email: ${ }^{2} z h a n g s h u n 0250 @ 163 . c o m, d o n g l i n i n g 910822 @ 163 . c o m$
}

Received 14 March 2016; accepted 23 April 2016; published 26 April 2016

Copyright (C) 2016 by authors and Scientific Research Publishing Inc.

This work is licensed under the Creative Commons Attribution International License (CC BY). http://creativecommons.org/licenses/by/4.0/

(c) (i) Open Access

\begin{abstract}
Studies of domestic and foreign scholars found that technological innovation is one of the key driving forces for economic growth. Venture capital (VC) had a new investment mechanism accompanied by the emergence technological innovation, and invested in a unique way and in a special operation mode, which determined the effective promotion of technological innovation. In this paper, the effect of VC on technological innovation was examined in two perspectives-"capitalincrease effect" and "innovation propensity-increase effect". Chinese provincial unbalanced panel data from 2009 to 2013 were gathered to verify the two effects above. And we also explored how VC affected regional innovation and its mechanism. The results showed that VC had a positive role in regional innovation promoting, and "capital-increase effect" can be verified. VC was to produce more innovations while reducing blind innovation input so as to improve innovation efficiency. The "innovation propensity-increase effect" can be verified.
\end{abstract}

\section{Keywords}

\section{VC, Regional Innovation, Innovation Efficiency}

\section{Introduction}

Technological innovation is one of the key driving forces for economic growth [1]-[3]. R\&D is an integral part for technological innovation and is also important to the value of the company [4] [5]. Venture capital (VC) has a new investment mechanism accompanied by the emergence technological innovation, and invests in a unique way and in a special operation mode, which determines the effective promotion of technological innovation and the commercialization of technology. Therefore, the study of VC on technological innovation is of great significance.

The first systematic study of the relationship between VC and innovation is Kortum and Lerner. They pub-

*Corresponding author.

How to cite this paper: Zhang, S. and Dong, L.N. (2016) Does VC Spur Regional Innovation? Open Journal of Social Sciences, 4, 122-130. http://dx.doi.org/10.4236/jss.2016.44017 
lished “Assessing the Contribution of VC to Innovation” in 2000. They used data from 20 US industries for nearly 30 years, in order to explore the role of VC in innovation. The study found that the increase of VC can bring a corresponding number of patent applications regarding industry level, and this effect is 3.1 times the R\&D. Tykvov used the German samples, applied the similar patent production function to Kortum and Lerner, and also verified the promotion of VC on technology innovation [6]. Jiangdian Chun and Huang Jintao combined with innovation inputs and outputs to study the impact mechanism of VC on enterprise innovation efficiency regarding enterprise level [7]. The empirical result shows that VC significantly increases the innovation efficiency, while there is no direct impact on innovation output, but they can significantly reduce R\&D, which shows that VC investment is not only a simple capital injection, but also a significant increase in the efficiency of enterprise output.

On the basis of the aforementioned studies, we use Chinese provincial unbalanced panel data from 2009 to 2013 to further explore the issues mentioned above to provide recommendations for the regional economy and the country's economy growth.

\section{Theoretical Analysis and Hypothesis}

Review of existing research found that academia had not yet formed a complete framework or even form a consistent conclusion for "the promotion of VC on innovation". Existing general conclusions can be summarized into two categories, namely, the theoretical literature and empirical literature. Theoretical research views that VC is a new corporate financing. VC has an advantage that it can provide funds which cannot be provided by traditional bank loans and securities to meet the needs of innovative high-tech enterprises. Namely VC promotes technological innovation by increasing the supply of capital. Empirical research views that VC mechanism and mode of operation are different from other funding source, providing capital for enterprises, using its own resources to provide management services to supervise the behavior of the entrepreneur risk, preventing moral hazard and increasing the success rate of innovation. That means VC increases the efficiency of technological innovation.

This chapter attempts to use mathematical analysis to put the two points of view of theoretical research and empirical research into a same framework, in order to solve the lack of a unified theoretical framework in this field.

\subsection{Effect Decomposition}

We assume that the whole society existing capital is $K_{0}$ and the average efficiency of the whole society to innovation is $\beta_{0}$ (i.e., the amount of innovation generated per unit of capital). The non-VC capital is $t$ times the VC capital in a single enterprise. The slope of traditional capital supply curve and demand curve are $m$ and $n$ ( $m>$ $0, n>0$ ). Considering a situation, we remove a part from the whole existing social capital, as the VC V. According to the theory of supply and demand, the capital supply of traditional capital markets will reduce $V$ and capital price will increase, which will resulted in inducing new capital (social idle funds) into capital market. That process is assumed incremental funding for $B$, which can be calculated $B=V m /(m+n)$ based on supply and demand function (obviously $B<V$ ). The increase of the capital market price reduces the amount of capital in equilibrium and total traditional capital will reduce to $K_{0}-V+B$. Meanwhile the total amount of VC is $V$. Assuming that all VC capital is invested in the enterprise, the total amount of corporate capital will be $V^{*}(1+t)$ (wherein the non-VC is $t V$ ). We assume that innovation efficiency will increase to $\beta_{1}$ after the entry of riskcapital into enterprises.

The amount of innovation of the whole society when the venture capital does not exist

$$
P_{0}=\beta_{0} K_{0}
$$

After the generation of VC, the amount of innovation of the whole society will change to

$$
P_{1}=\beta_{0}\left[K_{0}-(1+t) V+B\right]+\beta_{1}(1+t) V=P_{1}-P_{0}
$$

Differences before and after

$$
\begin{aligned}
\Delta P & =\beta_{0}\left[K_{0}-(1+t) V+B\right]+\beta_{1}(1+t) V-\beta_{0} K_{0} \\
& =\left(\beta_{1}-\beta_{0}\right)(1+t) V+\beta_{0} B \quad\left(\text { among them } \beta_{1}>\beta_{0}\right)
\end{aligned}
$$


The formula tells that the total social capital has increased. The "capital-increase effect" is $\beta_{0} B$, $\left(\beta_{1}-\beta_{0}\right)(1+t) V$ is the "innovation propensity-increase effect".

Next, we will analyze the mechanism of the above two effects on the theoretical point of view, and also answer the following questions: the reason VC can meet the capital needs that other funding cannot meet; the appearance of VC is not only a simple transfer of capital use, but also increases the total amount of social capital; the innovation efficiency will be improved after the entering of VC.

\subsubsection{Capital-Increase Effect}

From the macro level, the existence of capital-increase effect needs to be studied from the point of view of the total capital. The proof of this section is divided into two steps: VC can meet the capital needs that other funding cannot meet; the appearance of VC is not only a simple transfer of capital use, but it also increases the total amount of social capital.

1) VC Meets the Needs of Capital

Above all, we answer the first question. In order to find the reason why traditional capital cannot meet the capital demand in emerging markets, we elaborate the difference between venture capital and traditional capital from two perspectives which are the definition and characteristics.

The representative views for the definition of VC are as follows. According to the definition of the National VC Association (NVCA), VC is an equity capital which is invested to emerging and potential of small and medium enterprises by institutional investors [8]. Organization for Economic Cooperation and Development (OECD) Committee on Science and Technology Policy published a report entitled "Venture Capital and Innovation" in 1996. In the report, VC was defined as an act of equity capital investment which was usually happened in emerging enterprises or small and medium enterprises of great potential development. Its basic features are: long investment cycle, typically 3 to 7 years; in addition to capital investment, investors also offer business management advice and assistance; investors return on investment by equity transfer activities at the end of investment cycle. VC is a kind of high-risk high-yield investments and has features that it has a high degree of participation, invests in multiple rounds (Li Song, 2015), and focus on the interests of value-added.

To summarize the definition and features of VC, we can find that VC tends to invest in emerging areas, solving this problem some companies unable to obtain financing from traditional financial institutions place. In addition, VC also provides experience in business management for invested enterprises to achieve its value added.

2) Sources of VC Capital

We now answer the question that the appearance of VC is not only a simple transfer of capital use, but it also increases the total amount of social capital

Data from "China VC Yearbook" and "American VC Yearbook" presents that there is diversity for VC between different regions and during periods of the same region. Despite these differences, different regions or different periods of the same region do exist something in common, that is whether the above-mentioned companies financed by VC, structural or personal, they are all pursuing for profit. If these funds are not flowing into venture capital, it will likely be in the idle state and does not flow into production.

According to the theory of supply and demand, we will analyze how the loss of social idle funds to make up for the traditional capital. First we do not consider VC capital in social capital. According to the theory of supply and demand, extracting part of the traditional capital as VC will reduce the supply of funds and capital price will increase, which will result in inducing new capital (social idle funds) into capital market and a new equilibrium will form after the dynamic adjustment.

Price in the new equilibrium is higher than the original price equilibrium point, which means decimated capital is greater than attracted new capital. In conclusion, the emergence of VC caused three capital flows, namely (I) part of traditional funds transferred into VC market; (II) as a compensation fund, part of the idle funds transferred into traditional capital markets; (III) part of the idle funds transferred into VC market. Capital Flow II is a simple transfer of capital in different markets, and capital as a whole in the society does not increase. Capital Flow I and Capital Flow II lead to social idle capital flow into the capital market to increase quantity of total social capital, and thus the whole society produce more innovation due to the net increase in capital which constitutes the Capital-Increase Effect mentioned above.

We can draw the first two hypothesis of this article from the summary of the Capital-Increase Effect:

(I) VC has a positive impact on regional innovation outputs. If you stand in view of R\&D investment we will assure that (II) VC has a positive impact on regional innovation inputs. 


\subsubsection{Innovation Propensity-Increase Effect}

In this section, we will elaborate Innovation Propensity-Increase Effect from the perspective of business and industry. Based on enterprise perspective, VC's participation can urge enterprises to pay more attention to their innovation. VC promotes innovation efficiency through involved in the creation and management of enterprises to avoid the waste of resources, which is called "technical effect". Based on industry perspective, the existence of VC leads to capital configuration changes, causing more capital transferred from traditional industries to high-tech industries. High-tech industries means higher innovation efficiency, which results in the overall efficiency of social innovation improved. We call it the "structural effect".

1) Technical Effect

Technology effect views that that effect of VC, whose main targets are micro enterprises, comes from its high participation in business creation and management process. We will elaborate this effect according to the four stages of VC, which are fundraising, investment screening, investment management, capital exit.

a) Funds Raised Stage

Fundraising stage VC is the start of the VC process.VC firms look for suppliers of risk capital in the market. These providers may include pension funds, insurance, commercial banks, investment banks, large corporations and individual investors. They form a limited partnership to invest VC. A partnership venture investors generally act as limited partners and venture capitalists act as general partners or executive partners who is responsible for the operation and financial management decisions. Between the two partners is a kind of principal-agent relationship. This form of financing and management can help venture capitalists to avoid the problem of asymmetric information in the screening program and follow-up investment process. As the main provider of VC, venture capitalists generally are able to take higher risks in order to pursue higher earnings, which largely matches the characteristics and technological innovation itself, thus contributing to the company's innovation.

b) Investment Screening Stage

VC tends to invest in high-tech enterprises, and high-tech enterprises are often in high-risk and high-yield, which determines the importance of investment screening period. Complete VC decision-making process includes project collection and contact, preliminary analysis and judgment of project value (complete project report), due diligence (including legal and financial due diligence, to form the corresponding report), investment negotiations (conducted terms of the Investment Agreement Negotiations), transaction design (form investment proposals), investment decisions (the formal investment agreement) and value-added services and management (venture capitalist regularly report to the risk investors). Venture capitalists are in professional management capability which contributes to its rapid excavating valuable investment projects and eliminating information asymmetry in evaluation, selection and investment decision-making process in a certain degree, thus, reducing investment risk and improving the rate of technological innovation success. VC investment process is not one step, and capital is usually phased into risky business which forms a continuous monitoring of high-tech enterprises and technological innovation incentives to increase the probability of success.

c) Investment Management Stage

The investment management stage of venture capital is a long-term and continuous process. Risk investment is different from general corporate shareholders which has rich social resources and business management experience, as well as special investment enterprise purpose. That determines its ability to offer more professional and more valuable services to enterprises, including development strategy, market positioning, management suggestions, team building, financial marketing professional advice and suggestions. The purpose is to enhance the value of venture enterprises.

d) Capital Exit Stage

VC exit is the last link in the whole process, and there are two participants in this process. They are venture capitalist and outside investors. After the enterprises come to a relatively mature stage, venture capitalists will choose to sell the shares to outside venture investors, who may come from IPO or secondary market, management desires to acquire shares in the company, etc. For the enterprises, in the case of companies most in need of funds, it is possible to obtain support from the venture capital and management experience, and more able to carry out technological innovation, increase the probability of technological innovation and will be more efficient commercialization of innovations. Interdependence and mutual restraint between venture capitalists and venture entrepreneurs will promote innovation efficiency.

2) Structure Effect

Structural effects stand in the perspective of macro-industry. Capital transfers from traditional industries to 
high level of technological innovation industries, in which innovation efficiency is often higher. As to the whole society, due to the optimization of industrial structure adjustment, the amount of innovation increases.

From above three VC flows, capital in high-tech industry includes not only a simple shift from traditional industries over the capital, but also the early stage VC investment, which promotes the survival and development of high-tech industries, and then brings the traditional capital to invest the late period of high technology industries. Capital flow I and capital flow IV (late capital flow directly from the traditional industries to high-tech industries) constitute the capital flows from traditional industries to high-tech industry. The two part of the capital inflow into the high-tech industries which then brings the increase in the innovation constitute the complete structural effect.

The third hypothesis resulted in summary of innovation propensity-increase effect:

(III) VC positively affects the efficiency of regional innovation.

\section{Empirical Analysis}

\subsection{Sample}

The data of this paper comes from the Chinese provincial unbalanced panel data from 2009 to 2013. After final screening, we obtained 139 samples of data over 29 cities, including Anhui, Beijing, Fujian, Gansu, Guangdong, Guangxi, Guizhou, Hainan, Hebei, Henan, Heilongjiang, Hubei, Hunan, Jilin, Jiangsu, Jiangxi, Liaoning Province, Inner Mongolia Autonomous Region, Ningxia Hui Autonomous Region, Qinghai, Shandong, Shaanxi, Shanghai, Sichuan, Tianjin, Xinjiang, Yunnan, Zhejiang and Chongqing. Among them, regional per capita GDP, total import and export, regional GDP are derived from CEI. Education levels and regional wage are derived from "China Statistical Yearbook". Internal R\&D spending, the number of invention patent applications accepted, patent request authorization number are derived from the "China statistical Yearbook of Science and Technology". The amount of VC is derived from the "VC Yearbook".

\subsection{Variable Selection}

1) Explained Variable

Innovation inputs: internal R\&D expenditure logarithm; innovations outputs: the number of patent applications received and the number of invention patent applications authorized. Our patent can be divided into invention patents, utility model patents and appearance patent. And invention patent can best reflect a company's ability to innovate; Innovation Efficiency: this article refers Jiangdian Chun, Huang Jintao approach, using the ratio of the number of regional patent applications received to authorization number to measure R\&D investment.

2) Explanatory Variables

The main explanatory variables: VC. In this paper, we use VC logarithm to represent.

Control variables: refer to Yang Ye, Tan Yi, Shao Tong Yaoand Shao Tong Yao, Pan Yan, we select the wage level, the level of education and regional economic openness as control variables [9] [10].

Wages: the ratio of the average wage of the urban units to the area per capita GDP, Zhang Xi Ye, Cheng Ming Wang [11]; the level of education: the proportion of ordinary, specialist in the number of college students per million population in the end of the year; regional economic openness: the ratio of the total import and export to regional GDP.

\subsection{The Model}

Effect (1): impact of VC on innovation inputs

$$
\ln R D=\ln V C+\text { EDUPOP }+ \text { OPEN }+ \text { WAGEGDP }+\operatorname{lnGDP}
$$

Effect (2): impact of VC on innovation outputs

Yang Ye, Tan Yi, Shao Tong Yao (2012) have demonstrated serious multicollinearity between VC and innovation inputs will affect the role of VC on innovation, and with reference to Kortum and Lerner (2000) approach. In order to weaken the multicollinearity, we use a similar approach. To ensure the robustness of the model we construct the following two models. 


$$
\begin{aligned}
& \ln P A A_{-} I=\ln V C R D+\ln R D+\text { EDUPOP + OPEN + WAGEGDP } \\
& \operatorname{lnPA} \_ \text {I }=\ln V C R D+\ln R D+\text { EDUPOP + OPEN + WAGEGDP }
\end{aligned}
$$

Effect (3): impact of VC on innovation efficiency

We build a similar two models as to (2) as follows:

$$
\begin{aligned}
& \ln \mathrm{PAA} \_ \text {IRD }=\ln V \mathrm{C}+\mathrm{EDUPOP}+\mathrm{OPEN}+\mathrm{WAGEGDP} \\
& \ln \mathrm{PA} \_ \text {IRD }=\ln \mathrm{l} C+\mathrm{EDUPOP}+\mathrm{OPEN}+\text { WAGEGDP }
\end{aligned}
$$

\subsection{Empirical and Empirical Analysis}

In this paper, Stata12.0 software is used to estimate the model.

We first examine whether the venture will have an impact on innovation efficiency, which means to test the model (4) and the model (5). Due to economic development, geographical location and other factors are different between different provinces, so a fixed effect model is used to estimate the model, so as to the model (1) (2) (3).

The estimated results are shown in the following Table 1. VC has a positive impact on innovation efficiency which is expressed by the number of patent applications received, and empirical results are significant. However, VC has a positive impact on innovation efficiency which is expressed by the number of invention patent applications authorized, but empirical results are not significant, which is probably because patent application to the license is a better representation of enterprise innovation results.

A separate analysis of model (5) indicates that VC can promote regional innovation efficiency, empirical results established at the 5\% significance level. As to control variables, the level of education and regional economic openness has a positive influence on innovation efficiency. The higher the education level of a region, of course, the higher the quality of local staff which reflected in the company's innovation capability, and a more open area, the more the local economy and business exchanges with the oversea, the more we can promote the progress of local technology and improve innovation efficiency. So far, innovation propensity-increase effect has been verified. But how does the VC promote regional innovation and efficiency? The following we will explore the mechanism through examining capital-increase effect in which we focus on two factors: innovation outputs (number of patent applications) and innovation inputs (R\&D).

Firstly, considering the effect of VC on innovation inputs which is expressed by R\&D, empirical results are in the Table 2. The results show that VC has inhibitory effect on R\&D, and that such a negative effect established at the $10 \%$ significance level, which is different from large and most scholars who found that VC can promote $\mathrm{R} \& \mathrm{D}$ investment. The reason may be due to inconsistent research perspective. This paper uses regional data

Table 1. The impact of VC on regional innovation efficiency.

\begin{tabular}{ccc}
\hline & $(4)$ & $(5)$ \\
\cline { 2 - 3 } vc & paa_ird & pa_ird \\
& 0.0000963 & $0.0000439^{* * *}$ \\
edupop & $(1.09)$ & $(2.60)$ \\
& $0.00210^{*}$ & $0.000491^{* *}$ \\
open & $(1.96)$ & $(2.40)$ \\
& -0.00136 & $0.000950^{* *}$ \\
wagegdp & $(-0.66)$ & $(2.41)$ \\
& $-0.00502^{* * * *}$ & -0.000525 \\
_cons & $(-3.03)$ & $(-1.65)$ \\
& 0.00567 & 0.00000776 \\
$N$ & $(1.43)$ & $(0.01)$ \\
& 139 & 139 \\
\hline
\end{tabular}

$t$ statistics in parentheses. ${ }^{*} \mathrm{p}<0.1,{ }^{* *} \mathrm{p}<0.05,{ }^{* * *} \mathrm{p}<0.01$. 
Table 2. The impact of VC investment in regional innovation inputs.

\begin{tabular}{|c|c|}
\hline & (3) \\
\hline & rd \\
\hline \multirow[t]{2}{*}{ vc } & $-0.0130^{*}$ \\
\hline & $(-1.67)$ \\
\hline \multirow[t]{2}{*}{ edupop } & -0.0263 \\
\hline & $(-0.28)$ \\
\hline \multirow[t]{2}{*}{ open } & -0.0370 \\
\hline & $(-0.22)$ \\
\hline \multirow[t]{2}{*}{ wagegdp } & $0.806^{* * *}$ \\
\hline & (5.61) \\
\hline \multirow[t]{2}{*}{ gdp } & $1.466^{* * *}$ \\
\hline & (28.49) \\
\hline \multirow[t]{2}{*}{ _cons } & $-1.765^{* * *}$ \\
\hline & $(-3.02)$ \\
\hline$N$ & 139 \\
\hline
\end{tabular}

sample and the majority of scholars is to discuss on a business point of view.

We further explore the impact of venture capital on innovation output. The regression results in Table 3 shows that coefficients of the ratio of VC-R\&D and R\&D are significantly positive, indicating whether VC represented by the number of patent applications received or the number of invention patent applications authorized, VC on innovation outputs is significantly positive. For a specific area, the greater the amount of investment in VC, we can bring more innovation outputs. The innovation propensity-increase effect has been reflected.

We combine empirical results of the model (1) to the model (5), considering the effect of VC on innovation inputs, and innovation outputs and the efficiency of innovation, to analysis the mechanism how VC impacts innovation. The results of the model (5) show that VC can indeed play innovation propensity-increase effect, increasing innovation output per unit of R\&D. And also VC can promote the amount of VC in the case of a corresponding increase in the output of innovation, reflecting the capital-increase effect which has been verified in the model (3) and models (4). Results of the model (1) indicate that the presence of VC reduces regional innovation and stifles innovation activities. But in reality, combining the empirical results of the five models, you will see how VC promotes regional innovation efficiency. Once the VC enters into venture enterprises, the caution and profit driven determines its $\mathrm{R} \& \mathrm{D}$ is not large or aimless, instead, is more careful of every innovation activity and innovation investment. And purposelessness R\&D reduced, therefore the regional innovation outputs show a corresponding reduction. In summary, VC can reduce regional innovation inputs and increasing regional innovation outputs, namely VC can increase innovation output per unit of innovation input or improve the efficiency of regional innovation.

\section{Conclusions and Policy Recommendations}

\subsection{Conclusions}

In this paper, theoretical analysis and empirical analysis are used. At first, this paper reviews the related literature at home and abroad. In the part of theoretical analysis, the effect of VC on technological innovation was examined in two perspectives- "capital-increase effect" and "innovation propensity-increase effect". And we tested the two kinds of effects through the empirical research in order to explore the impact mechanism of venture capital on Regional Innovation. The results showed that VC had a positive role in regional innovation promoting, and "capital-increase effect" can be verified. VC was to produce more innovations while reducing blind 
Table 3. The impact of VC on the innovative outputs.

\begin{tabular}{ccc}
\hline & $(1)$ & $(2)$ \\
\cline { 2 - 3 } vcrd & pa__i & pa_i \\
& $0.0526^{* *}$ & $0.0446^{* *}$ \\
rd & $(2.13)$ & $(2.08)$ \\
& $1.419^{* * * *}$ & $1.354^{* * *}$ \\
edupop & $(22.19)$ & $(24.38)$ \\
& 0.0340 & 0.0835 \\
open & $(0.18)$ & $(0.51)$ \\
& -0.493 & 0.386 \\
wagegdp & $(-1.45)$ & $(1.31)$ \\
& $-0.880^{* * * *}$ & $-0.578^{* * *}$ \\
_cons & $(-3.22)$ & $(-2.44)$ \\
& $-10.42^{* * *}$ & $-11.57^{* * *}$ \\
$N$ & $(-10.00)$ & $(-12.78)$ \\
& 139 & 139 \\
\hline
\end{tabular}

$t$ statistics in parentheses. ${ }^{*} \mathrm{p}<0.1,{ }^{* *} \mathrm{p}<0.05,{ }^{* * *} \mathrm{p}<0.01$.

innovation input so as to improve innovation efficiency. The "innovation propensity-increase effect" can be verified.

\subsection{Policy Recommendations}

Research findings above have verified that the existence of "capital-increase effect" and "innovation propensity-increase effect" and found that social idle funds is an important source of VC. Guiding social idle capital into the VC can significantly improve the innovation.VC involved in the process of risk enterprise technology innovation through its various stages, guides the enterprises to enter the high-tech industries, So as to improve the efficiency of enterprise innovation. The policy recommendations of this paper are as follows: 1) improve the VC investing and financing environment and establish good cooperation environment of VC and corporate; 2) to guide the parties to enter the field of VC funds and to guide the VC into high-tech industries; 3) to establish a more perfect innovative protection system and ensure effective implementation of innovative protection strategies for facilitating innovations into economic value; 4) different regional governments need to develop different innovative protection measures, according to the actual and regional situation specialties.

\subsection{Limitations of the Study}

1) Availability of data is limited due to small sample size, which may affect the reliability of the empirical results, and further research needs to be expanded using more complete data samples.

2) Theoretical models of the impact of R\&D investment on innovative are limited in existing literature, leading to the empirical model of this article can only be established on theoretical analysis and empirical research. So, model bias may exist which could affect the scientificalness of the research.

\section{References}

[1] Aghion, P. and Howitt, P. (1992) A Model of Growth through Creative Destruction. Econometrica, 60, 323-351. http://dx.doi.org/10.2307/2951599

[2] Romer, P.M. (1986) Increasing Returns and Long-Run Growth. The Journal of Political Economy, 94, $1002-1037$. http://dx.doi.org/10.1086/261420

[3] Romer, P.M. (1990) Endogenous Technological Change. Journal of Political Economy, 98, 32-34. http://dx.doi.org/10.1086/261725 
[4] Lev, B. and Sougiannis, T. (1996) The Capitalization, Amortization, and Value-Relevance of R\&D. Journal of Accounting and Economics, 21, 107-138. http://dx.doi.org/10.1016/0165-4101(95)00410-6

[5] Luo, T., Zhu, Q. and Li, D. (2009) Analysis on the Relationship between R\&D Investment and Firm Value. Financial Research, 6.

[6] Tykvova, T. (2000) VC in Germany and Its Impact on Innovation. The 2000 EFMA Conference, Athens, Social Science Research Network Working Paper.

[7] Chun, J.D. and Huang, J.T. (2015) VC on Innovation Efficiency Mechanism. Chinese Universities Social Science, 6, 140-151, 155.

[8] http://www.nvca.org

[9] Yang, Y., Tan, Y. and Shao, T.Y. (2012) VC and Innovation: Excitation, Inhibition or Neutral—Evidence from Chinese Provincial Panel. Economic Problems, 3, 9-13.

[10] Shao, T.Y. and Yan, P. (2011) VC, R\&D Investment and Regional Innovation-Based on Provincial Panel Study Trademark. Science Studies, 5, 793-800.

[11] Zhang, X. and Wang, C.M. (2014) Reasonableness of the Minimum Wage in Shanghai-An Empirical Analysis Based on the Angle of Minimum Wage Earners. Northeast Economic Management, 10, 12-16. 